\title{
Utilização do Persea major (pau-de-andrade) em ferida de equino
}

Luane Camargo Zeni", Pedro Lara, Eros Luis de Sousa, Pedro Vicente Michelotto Jr., Luciana Doria Ribeiro Cabral

Pontifícia Universidade Católica do Paraná (PUCPR), Curitiba, PR, Brasil

*Autor correspondente

e-mail: luanezeni@yahoo.com.br

\section{Resumo}

A Persea major, popularmente conhecida como pau-de-andrade ou pau andrade, tem um grande potencial de bioatividades. 0 pau-de-andrade pertence à família Lauraceae, com distribuição ampla no estado do Paraná. Contudo, o uso do dessa planta é restrito às comunidades tradicionais, as quais detêm o conhecimento empírico da utilização para o tratamento de feridas e distúrbios gástricos. Diariamente, os médicos veterinários atendem pacientes com diversos tipos de lesões e ferimentos, sendo necessária a escolha da melhor forma de tratamento para que ocorra a reparação tissular, e cuja aplicação da terapêutica depende da localização do ferimento, grau de lesão tecidual, tipo de secreção e de cicatrização observada. Por não se encontrar vasta literatura sobre a utilização da P. major em manejo de feridas, objetivou-se avaliar o seu uso durante o processo de cicatrização de uma ferida linear, localizada na face plantar da falange proximal do membro posterior esquerdo (MPE) de um equino. Um equino macho, Sela Holandesa, 12 anos, $600 \mathrm{~kg}$, foi atendido na Unidade Hospitalar de Animais de Fazenda e Equinos - PUCPR, apresentando um corte linear com $12 \mathrm{~cm}$ de comprimento e $2 \mathrm{~cm}$ de profundidade, na região plantar da quartela de MPE. Durante a inspeção da ferida, constatou-se a presença de secreção purulenta, grande sensibilidade à palpação e sinais locais de inflamação. Ao exame clínico, o animal não apresentou alterações nos parâmetros vitais. Foi realizada tricotomia ao redor da lesão e, em seguida, limpeza da ferida com solução fisiológica $0,9 \% \mathrm{NaCl}$ com posterior secagem utilizando gaze estéril. Para os curativos, com auxílio de luva estéril, foi utilizada a mucilagem da casca da árvore, obtida somente através da fervura da casca do pau-de-andrade com $250 \mathrm{~mL}$ de água, aplicada diretamente na ferida, compressa estéril para cobrir a lesão, algodão hidrófilo e atadura para bandagem. Os curativos eram trocados diariamente, sempre de maneira estéril, a fim de reduzir a contaminação. Este tratamento foi realizado durante o período de 30 dias. Para evitar a aderência na bainha dos tendões flexores do MPE, foi realizada fisioterapia com caminhada duas vezes ao dia, durante trinta 
minutos, em todos os dias do tratamento. A P. major é muito utilizada pela população em geral para cicatrização de feridas, pois os resultados rápidos e satisfatórios são devidos à presença de taninos na composição da casca, os quais estão diretamente ligados ao processo cicatricial. A utilização de fitoterápicos na clínica de equinos é muito realizada no manejo de feridas, contudo, seguindo apenas os conhecimentos empíricos e popular. Assim, o emprego do extrato de P. major no processo cicatricial de feridas de equinos ainda possui um campo aberto para estudos. A casca apresenta alto caráter mucilaginoso em contato com a água. Quando em presença de água, as mucilagens incham e tomam um aspecto particular de soluções coloidais ou géis. 0 uso da mucilagem está relacionado, entre outros efeitos terapêuticos, a sua ação protetora das mucosas inflamadas, impedimento da ação de substâncias irritantes e diminuição dos estados inflamatórios, aliviando a dor. Com isso, durante o tratamento com a utilização da mucilagem, obtida através do pau-deandrade, na ferida do caso exposto, a evolução do processo cicatricial foi notável logo nos primeiros dias de uso, quando a profundidade da lesão reduziu de forma abrupta, sendo notável o reparo da lesão constante. Na última semana do tratamento, a ferida já se mostrava em fase final de remodelação e o animal não demonstrava mais sinais inflamatórios no local, portanto, recebeu alta após 30 dias de tratamento. Com o acompanhamento da lesão durante um mês de tratamento, foi possível concluir que a utilização de Persea major (pau-de-andrade) mostra-se eficiente para a cicatrização de feridas em equinos, sendo possível e plausível continuar estudando sobre este fitoterápico e seus benefícios aplicados à clínica de equinos.

Palavras-chave: Fitoterápico. Feridas. Persea major. 